\title{
Pengaruh Pemberian Remunerasi Direksi Terhadap Kinerja Keuangan Perusahaan Publik di Indonesia
}

\author{
Amadea Paulina Pangestu, Selly Agustia, Rathria Arrina Rachman *) \\ Sekolah Bisnis dan Ekonomi-Universitas Prasetiya Mulya \\ BSD City Kavling Edutown I.1 , Jl. BSD Raya Utama, BSD City, Tangerang 15339
}

\section{Keywords :}

Director Remuneration, Generalized Least Square, Agency Theory, Indonesia

\section{Kata Kunci :}

Remunerasi Direksi, Generalized Least Square, Teori Agensi, Indonesia

\section{* Corres ponding Author:} rathria.rachman@pmbs.ac.id

\begin{abstract}
This research was conducted to study the relationship between remuneration of directors and financial performance of companies in Indonesia. Based on the Agency Theory (Jensen and Meckling, 1976), remuneration given to directors will improve the company's financial performance because the provision of good remuneration will harmonize the interests of the principal (shareholders) and agents (company directors). This study uses a sample of 147 publicly-listed companies spread across 10 sectors and listed on the Indonesia Stock Exchange over 2013 to 2017. Using panel data regression methods with Generalized Least Squares (GLS), the results of this study indicate that the remuneration of directors has a positive relationship to several financial performance indicators, namely Return On Assets (ROA) and Return On Equity (ROE, where the higher the remuneration given to directors will improve the company's financial performance. Thus, this results is consistent with the Agency Theory.
\end{abstract}

\section{Sari Pati}

Penelitian ini dilakukan untuk mempelajari hubungan antara remunerasi direksi dan kinerja keuangan perusahaan di Indonesia. Berdasarkan teori agensi (Jensen dan Meckling, 1976), pemberian remunerasi kepada direksi akan meningkatkan kinerja keuangan perusahaan karena pemberian remunerasi yang baik akan menyelaraskan kepentingan antara principal (pemegang saham) dan agents (direksi perusahaan). Penelitian ini menggunakan sampel sebanyak 147 perusahaan terbuka yang tersebar di 10 sektor dan tercatat di Bursa Efek Indonesia antara periode tahun 2013 sampai 2017. Menggunakan metode regresi data panel dengan Generalized Least Squares (GLS), hasil penelitian ini menunjukkan bahwa remunerasi direksi memiliki hubungan yang positif terhadap beberapa indikator kinerja keuangan, yaitu Return On Assets (ROA) dan Return On Equity (ROE, dimana semakin tinggi remunerasi yang diberikan kepada direksi akan meningkatkan kinerja keuangan perusahaan. Dengan demikian, hal ini selaras dan konsisten dengan teori agensi. 


\section{Pendahuluan}

Smith (1776) menekankan bahwa alokasi sumber daya manusia yang efektif merupakan hal yang penting bagi pertumbuhan ekonomi. Dengan meningkatnya persaingan usaha, kualitas pekerja yang cakap menjadi salah satu tuntutan perusahaan agar mampu bersaing dengan kompetitor (Idris, 2016). Tanpa adanya pekerja, operasional perusahaan tidak akan berjalan dengan baik. Sehingga peran sumber daya manusia patut dihargai oleh perusahaan.

Setiap organisasi atau perusahaan memiliki struktur pemberian remunerasi yang berbeda-beda yang disesuaikan dengan hasil kinerja dan posisi jabatan pegawai (Fitria et al.,2014). Dalam Kamus Besar Bahasa Indonesia (KBBI, 2016), remunerasi memiliki arti yaitu pemberian hadiah, penghargaan atau imbalan atas jasa dan kontribusi yang diberikan seseorang pada sebuah perusahaan atau organisasi. Meskipun setiap perusahaan memiliki struktur remunerasi yang berbeda-beda namun pemberian remunerasi memiliki tujuan yang sama, yakni menarik calon karyawan dengan kualitas dan kompetensi sesuai dengan syarat perusahaan, mempertahankan karyawan yang memiliki prestasi dan berkontribusi besar kepada perusahaan, dan meningkatkan motivasi kerja (Hutapea dan Thoha, 2008). Selain itu, komponen yang digolongkan sebagai remunerasi adalah gaji tetap dan insentif atau tantiem, yang diberikan berdasarkan key performance indicator, kesehatan perusahaan (Prasidhanto, 2012) dan dengan dasar prinsip keadilan, meningkatkan motivasi, kompetitif, tepat, sesuai dengan ketetapan perusahaan, dan seimbang (Iskan, 2013)

Menurut Becker (1962), kesuksesan sebuah perusahaan dipengaruhi oleh investasi yang efisien pada sumber daya manusia. Heskett et al. (1994) dalam teorinya yaitu service-profit chain menyinggung hubungan antara pelayanan yang diberikan oleh karyawan terhadap profitabilitas sebuah perusahaan atau bentuk usaha. Dalam penelitiannya, Hesket et al. (1994) menyatakan bahwa penilaian akan seberapa efektif dan sukses pekerja dalam perusahaan dapat terlihat dari kinerja keuangan perusahaan karena kinerja perusahaan secara keseluruhan tidaklah terlepas dari kinerja karyawan yang menopang kegiatan perusahaan, tidak terkecuali eksekutif di dalam perusahaan. 
Dalam penelitian ini, eksekutif menjadi fokus utama sebagai pengaruh penilaian terhadap kinerja keuangan perusahaan. Eksekutif merupakan pemimpin tertinggi yang memiliki peranan penting dalam keberlangsungan perusahaan, salah satunya terkait pengambilan keputusan rencana strategis untuk masa depan perusahaan yang dapat memberikan dampak bagi perusahaan (Naciri, 2010). Menurut UUPT No. 40 tahun 2007, direksi adalah pihak yang harus bertanggung jawab atas kerugian yang ditimbulkan jika melakukan kesalahan atau lalai dalam tugas. Dengan demikian, direksi suatu perusahaan memiliki tugas untuk terus membawa perusahaan menjadi lebih baik karena segala tindakan yang diambil oleh direksi dapat memberikan dampak pada pemegang saham sebagai principal. Pada penelitian ini, eksekutif yang dimaksud adalah direksi dalam perusahaan.

Berdasarkan pasal 1 ayat (5) Undang-undang Perseroan Terbatas Nomor 40 tahun 2007 (UUPT), direksi merupakan organ dari perusahaan yang memegang kekuasaan dan bertanggung jawab penuh atas perusahaan untuk kepentingan perusahaan sesuai dengan maksud dan tujuan Perseroan serta mewakili Perseroan, baik di dalam maupun di luar pengadilan sesuai dengan ketentuan anggaran dasar.

Balsam (2002) mengatakan bahwa remunerasi eksekutif merupakan hal yang penting bagi perusahaan. Pemberian remunerasi bagi direksi menjadi penting untuk dapat menyelaraskan kepentingan eksekutif dengan shareholders (Kostyuk et al., 2016; Pearce dan Robinson, 2007). Remunerasi yang diterima oleh jajaran direksi haruslah sesuai dengan ekspektasi atau pencapaian perusahaan agar kepentingan direksi dapat sejalan dengan kepentingan pemegang saham sehingga dapat memberikan kesejahteraan bagi pemegang saham (Pearce dan Robinson, 2007).

Penelitian mengenai hubungan antara remunerasi direksi dan kinerja keuangan perusahaan sudah pernah dilakukan sebelumnya, baik di luar negeri maupun dalam negeri namun menunjukan hasil yang beragam. Beberapa peneliti menemukan tidak ada hubungan antara remunerasi direksi dan kinerja keuangan perusahaan (Bonsu dan Lutta, 2016; Khaparde dan Chincokar, 2013). Di sisi lain, terdapat pula yang berpendapat bahwa remunerasi direksi memiliki dampak positif terhadap kinerja keuangan perusahaan (Carpenter dan Sanders, 2002; Cao, et a1., 2009; Krauter, 2013; Ismail, et al., 
2014; Muller, 2014; Subekti dan Sumargo, 2015; serta Smirnova dan Zavertiaeva, 2017) atau memiliki dampak negatif terhadap kinerja keuangan perusahaan (Balafas dan Florackis, 2014; Ogbeide dan Akanji, 2016).

Keberagaman dalam fenomena dan hasil penelitian menarik perhatian peneliti untuk melakukan penelitian ini di Indonesia dengan jangka waktu yang berbeda dan melihat apakah hasil dari penelitian sebelumnya serupa dengan Indonesia serta melihat pengaruh pemberian remunerasi direksi terhadap kinerja perusahaan terkait. Dalam penelitian ini, penulis akan fokus pada remunerasi finans ial yang diterima secara langsung oleh direksi. Remunerasi finansial yang diterima langsung ini dinilai memiliki pengaruh cukup besar terhadap performa seseorang dalam arti dapat memicu dan memotivasi serta mempengaruhi kinerja orang apakah terdaapat hubungan antara remunerasi direksi dan kinerja keuangan perusahaan di Indonesia.

\section{Studi Literatur dan Penge mbangan Hipotesis}

\section{Agency Theory}

Agency theory merupakan teori mengenai hubungan antara seseorang atau lebih (principal) dan pihak lainnya (agents) dengan memberikan kekuasaan dalam pengambilan keputusan terkait operasional perusahaan kepada agent sebagai pihak pelaksana dari segala kepentingan principal (Jensen dan Meckling, 1976). Menurut Spremannet al., (1987), principal adalah pemilik yang memberikan mandat kepada agent sedangkan agent merupakan seseorang dengan kekuasaan dan hak dalam pengambilan keputusan dengan tugas melaksanakan mandat principal dan terikat oleh kontrak. Penentuan biaya dan imbalan untuk seluruh pihak yang bersangkutan akan terpapar dalam kontrak. Pemberian insentif yang sesuai dan tepat kepada agent dilakukan untuk menghindari aktivitas menyimpang yang dapat terjadi (Jensen dan Meckling, 1976).

Dalam kenyataannya, hubungan antara direksi dan shareholders tidak selalu baik karena adanya perbedaan kepentingan (conflict of interest) dan asymmetric information. Konflik ini lebih 
dikenal sebagai Agency Problem atau Principal-Agent Problem, yang dapat muncul karena adanya ketidak sepahaman atau perbedaan hasil yang diberikan oleh agent dengan ekspektasi principal.

Adanya informasi yang as imetri atau tidak sempurna menjadi salah satu akar permasalahan yang menimbulkan kesenjangan antar pihak yang terlibat dalam perusahaan. Sebagai contohnya, adanya anggapan bahwa pengetahuan principal lebih luas dibandingkan dengan pengetahuan agent (Prasetyantoko, 2013). Agent dan principal memiliki sudut pandang yang berbeda dan kepentingan berbeda, agent cenderung bertindak sesuai dengan kepentingannya sendiri untuk memaksimalkan keuntungan bagi dirinya (Prasetyantoko, 2013).

Menurut Jensen dan Meckling (1976), terdapat beberapa cara untuk memperkecil terjadinya principal-agent problem yaitu: 1) Stock option, berupa pemberian persentase atau kepemilikan saham kepada agent agar agent bekerja lebih baik karena agent memiliki investasi dalam perusahaan pula dan 2) Insentif, yang dilakukan untuk memotivasi agent agar dapat meningkatkan kinerjanya.

\section{Peranan dan Tanggung Jawab Direksi}

Dalam perusahaan, direksi yang berada dalam perusahaan memiliki peranan untuk memonitor perusahaan, mengambil keputusan serta mengembangkan strategi perusahaan yang bersangkutan (Ghosh, 2006). UUPT No. 40 tahun 2007 secara tegas menjelaskan bahwa direksi harus bertanggung jawab atas kerugian yang ditimbulkan jika melakukan kesalahan atau lalai dalam tugas. Pengurusan yang dilakukan direksi harus sesuai dengan tujuan dan kepentingan Perseroan serta dija lankan dengan itikad baik dan penuh tanggung jawab. Maka dari itu, direksi dari sebuah perusahaan memiliki tugas untuk terus membawa perusahaan menjadi lebih baik karena segala tindakan yang diambil oleh direksi dapat memberikan dampak pada pemegang saham sebagai principal.

Menurut Solomon (2004), adanya peningkatan kinerja perusahaan tentunya dapat memuaskan pemegang saham dan eksekutif sehingga bisa mendapatkan imbalan berupa kenaikan gaji atau remunerasi. Adanya penambahan remunerasi direksi diberikan dengan tujuan memotivasi kinerja direksi agar dapat lebih baik dari sebelumnya.

\section{Direksi dan Remunerasi di Indonesia}


Dalam Pasal 3 ayat (1) POJK No. 33 Tahun 2014 dan UUPT No. 40 Tahun 2007, tertulis bahwa pengangkatan, penggantian, dan pemberhentian Direksi dilakukan berdasarkan keputusan yang terdapat dalam Rapat Umum Pemegang Saham (RUPS). Pengangkatan dan pemberhentian anggota direksi dalam RUPS dilakukan dengan pemungutan suara (voting). Selain itu, penentuan remunerasi direksi juga ditentukan dalam RUPS.

Menurut Huse (2007:78), remunerasi merupakan salah satu bentuk dorongan atau insentif yang dapat diberikan kepada direksi agar dapat melakukan tanggung jawab sesuai dengan kepentingan pemegang saham. Insentif yang merupakan remunerasi langsung ini diberikan perusahaan dengan tujuan untuk meningkatkan produktivitas direksi (Hariandja, 2002:276). Perencanaan remunerasi terbentuk karena adanya pengaruh manajerial yang mengarah kepada hasil yang menguntungkan eksekutif perusahaan (Bebchuk dan Fried, 2003). Ketika direksi merasa diuntungkan dan termotivasi, maka direksi terdorong agar memberikan kinerja yang lebih maksimal.

Berdasarkan jenisnya, remunerasi diklasifikasikan menjadi 2 bentuk yakni remunerasi finansial dan non finansial. Suyanto (2007:181) memaparkan 2 bentuk remunerasi yang dapat diberikan untuk eksekutif perusahaan, yaitu 1) Remunerasi Non-Finansial, imbalan yang sering kali dinilai karyawan sangat tinggi dan dihargai yang diterima da lam bentuk imbalan karir dan sosial serta cenderung berkaitan dengan kepuasan yang diberikan kepada seseorang ketika berhasil menyelesaikan pekerjaannya dengan baik. 2) Remunerasi Finansial, memiliki tujuan untuk menarik sumber daya manusia yang potensial, mempertahankan pekerja yang berkualitas dalam perusahaan, mencapai keunggulan kompetitif, peningkatan produktivitas, mempermudah sasaran strategis, pengokohan dan penentuan struktur organisasi perusahaan dan melakukan pembayaran sesuai dengan aturan hukum yang berlaku. Menurut Hariandja (2002), remunerasi finansial terdiri dari remunerasi langsung seperti gaji, upah, bonus, insentif dan tunjangan lainnya dan remunerasi tidak langsung seperti tunjangan yang tidak terkait langsung dengan kinerja dan kepuasan pekerja.

Terdapat beberapa jenis remunerasi atau imbalan kerja dalam PSAK 24 yaitu imbalan kerja jangka pendek (gaji, iuran jaminan sosial, cuti tahunan, cuti sakit, bagi laba dan bonus, dan lainnya), 
imbalan pasca kerja (imbalan pensiun, imbalan asuransi jiwa pasca kerja, dan lainnya) dan imbalan kerja jangka panjang (cuti besar/cuti panjang, penghargaan masa kerja, dan lainnya).

\section{Remunerasi dan Keberhasilan Perusahaan}

Hubungan antara remunerasi dan kinerja perusahaan ditemukan dalam beberapa penelitian sebelumnya. Beberapa peneliti berpendapat bahwa remunerasi eksekutif tidak memiliki hubungan signifikan terhadap kinerja perusahaan (Bonsu dan Lutta, 2016; Khaparde dan Chincokar, 2013). Penelitian Bonsu dan Lutta (2016) menggunakan ROE dan ROA sebagai variabel dependen dengan remunerasi eksekutif berupa gaji dan bonus sebagai variabel independennya. Berdasarkan penelitian tersebut, tidak ada hubungan antara kedua variabel disebabkan karena CEO lebih menginginkan untuk melakukan peningkatan pendapatan perusahaan dan bukan laba atau profitabilitas perusahaan. Khaparde dan Chincokar (2013) juga tidak menemukan adanya hubungan antara remunerasi CEO dan kinerja perusahaan dengan menggunakan pendapatan dan EBITDA per karyawan sebagai pengukuran kinerja keuangan perusahaan pada penelitiannya.

Di lain pihak terdapat peneliti yang menyatakan adanya hubungan positif dari kedua variabel tersebut (Kube, 2008; Cao et al., 2009; Krauter, 2013; Muller, 2014; Ismail et al., 2014; Subekti dan Sumargo, 2015; Smirnova dan Zavertiaeva, 2017). ROA dan ROE merupakan komponen kinerja perusahaan yang sering digunakan dalam penelitian sejenis, beberapa penelitian yang menggunakan ROA dan ROE sebagai variabel dependen dan variabel independen berupa remunerasi CEO (gaji dan bonus) ada lah Ismail et al. (2014), Kube (2008), Krauter (2013). Penggunaan ROA sebagai pengukur kinerja perusahaan sangat umum digunakan pada penelitian sebelumnya yang mendapatkan hasil bahwa adanya hubungan positif antara ROA dan remunerasi CEO, beberapa diantaranya dilakukan oleh Carpenter dan Sanders (2002), Muller (2014), Subekti dan Sumargo (2015), dan Smirnova dan Zavertiaeva (2017). Hubungan positif terhadap kinerja perusahaan juga ditemukan oleh Deysel dan Kruger (2015) dengan variabel independen berupa insentif jangka panjang dan variabel dependen adalah performa pasar yang diukur dengan harga saham. 
Selain itu, terdapat hasil yang menyatakan bahwa remunerasi eksekutif dan kinerja keuangan perusahaan memiliki hubungan negatif seperti pada penelitian Balafas dan Florackis (2014) dan Ogbeide dan Akanji (2016). Penelitian Ogbeide dan Akanji (2016) dilaksanakan dengan variabel dependen yang digunakan merupakan Earnings Before Interest and Tax (EBIT) dan variabel independen berupa remunerasi eksekutif, ukuran perusahaan yang diukur dengan total aset, dan ukuran dewan. Hasil yang serupa juga didapatkan oleh Balafas dan Florackis (2014) yang menggunakan perusahaan pada London Stock Exchange sebagai sampel penelitian serta variabel dependen dan independen yang digunakan adalah ROA dan remunerasi CEO. Menurut Balafas dan Florackis (2014), alasan atas hubungan negatif antara ROA dan remunerasi CEO yang dilakukannya adalah karena adanya faktor risiko seperti coskewness dan kurtosis, risiko unsystematic, dan tenor pada CEO baru dimana perusahaan berusaha untuk menetapkan standar remunerasi baru.

Hal yang menarik selanjutnya terdapat pada penelitian yang dilakukan oleh Kutum (2015) yang memiliki hasil yang berbeda pada setiap indikator kinerja keuangan perusahaan yang diteliti yakni ROA, ROE, dan profit margin. Hasil penelitian menemukan adanya hubungan positif antara remunerasi CEO dan ROA namun remunerasi CEO tidak mempunyai hubungan dengan ROE dan profit margin. Berbeda dengan Kutum (2015), penelitian yang dilakukan Demirer dan Yuan (2013) menemukan adanya perbedaan hasil yang disesuaikan dengan variabel dependen yang digunakan, remunerasi yang diukur dalam bentuk gaji memiliki hubungan negatif terhadap kinerja perusahaan sebaliknya hubungan negatif terhadap kinerja perusahaan didapatkan pada remunerasi dengan bentuk bonus dan non-ekuitas. Menurut Demirer dan Yuan (2013), hasil penelitian tersebut didasari dengan alasan bahwa sang pembuat keputusan (decision maker) lebih fokus pada pengambilan keputusan jangka pendek karena keputusan dalam jangka pendek dinilai akan memberikan dampak yang positif pada kinerja jangka panjang nantinya.

\section{Pengembangan Hipotesis}




\section{Gambar 1. Kerangka Pemikiran}

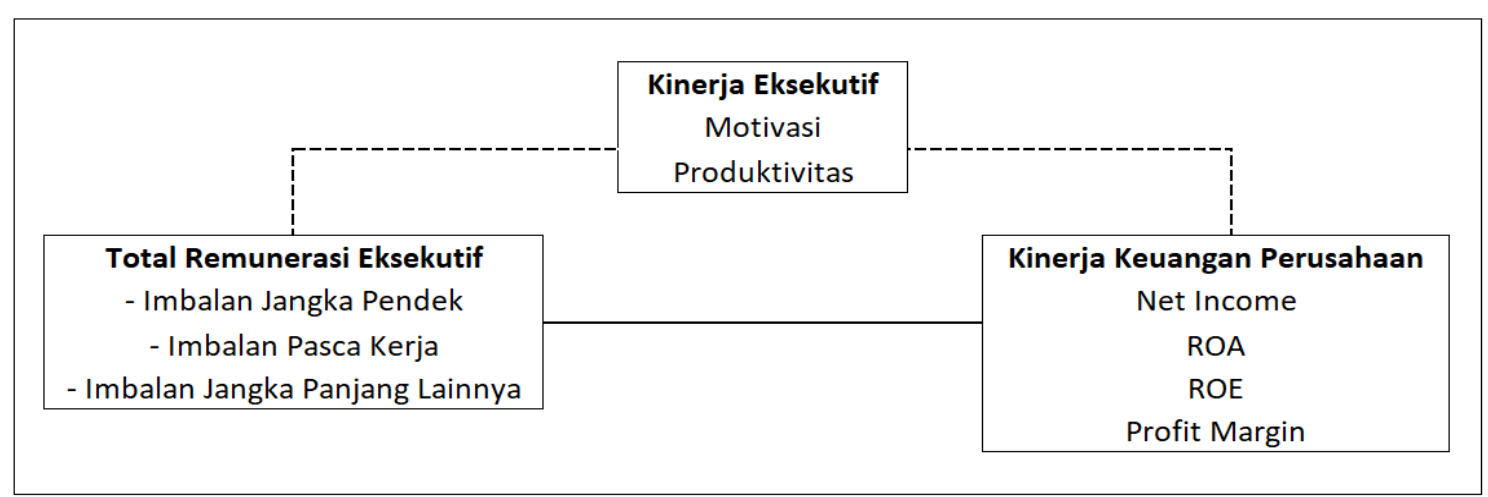

Sumber: Hasil olahan penulis

Dalam penelitian ini, penulis memiliki asumsi bahwa pemberian remunerasi akan mempengaruhi kinerja keuangan perusahaan secara tidak langsung dimana pengaruh dari pemberian remunerasi akan terlihat dari adanya sumber daya yang termotivasi, semakin produktif dan puas dengan remunerasi yang diterima maka akan mempengaruhi kinerja perusahaan secara positif. Penelitian Anggriawan et al. (2015) menyatakan bahwa keberhasilan perusahaan diawali dengan pemberdayaan sumber daya manusia yakni orang-orang yang menyediakan tenaga, bakat, kreativitas serta semangat bagi perusahaan. Bentuk sumber daya tersebutlah yang menjadi roda penggerak utama dalam perusahaan, terutama sumber daya manusia yang berada di level atas perusahaan yaitu direksi. Pada penelitian ini, penulis fokus pada hubungan yang diberikan remunerasi direksi kepada kinerja keuangan perusahaan tanpa membahas mengenai kinerja direksi. Hipotesa pada penelitian ini yaitu pemberian remunerasi direksi memiliki hubungan positif dengan kinerja perusahaan. Hal ini serupa dengan penelitian Kube (2008), Cao et al. (2009), Krauter (2013) dan Ismail et al. (2014).

$\mathbf{H}_{\mathbf{0}}$. Pemberian remunerasi kepada Direksi tidak berpengaruh positif terhadap kinerja keuangan perusahaan.

$\mathbf{H}_{1}$. Pemberian remunerasi kepada Direksi berpengaruh positif terhadap kinerja keuangan perusahaan.

\section{Metode Penelitian}




\section{Populasi dan Sampel}

Populasi dari data penelitian ini adalah sebanyak 578 perusahaan terbuka yang berada di 10 sektor yang tercatat di Bursa Efek Indonesia (BEI) berdasarkan Global Industrial Classification Standard (GICS) selama tahun 2013-2017. Dari seluruh perusahaan tersebut, dipilih sebanyak 147 perusahaan sebagai sampel penelitian yang memenuhi kriteria pemilihan sampel sebagai berikut:

1. Perusahaan terbuka yang terdaftar di Bursa Efek Indonesia (BEI)

2. Perusahaan melakukan Initial Public Offering (IPO) sebelum tahun 2012

3. Perusahaan memiliki laporan keuangan lengkap selama 5 tahun terakhir (2013-2017)

4. Perusahaan memiliki data lengkap mengenai remunerasi dewan direksi-nya

Sumber data penelitian berasal dari Bloomberg Terminal dan laporan keuangan perusahaan yang diambil dari website resmi perusahaan dan website Bursa Efek Indonesia.

Tabel 1. Pemilihan Sampel Penelitian

\begin{tabular}{|l|l|l|}
\hline Krite ria & $\begin{array}{l}\text { Jumlah } \\
\text { Perusahaan }\end{array}$ & Jumlah \\
& Obse rvasi \\
\hline Perusahaan yang terdaftar di Bursa Efek Indonesia (BEI) selama 5 tahun & 578 & 2,890 \\
\hline Perusahaan yang melakukan IPO sebelum tahun 2012 & 447 & 2.235 \\
\hline Perusahaan yang memiliki laporan keuangan lengkap tahun 2013 - 2017 & 172 & 860 \\
\hline Perusahaan yang memiliki data remunerasi direksi & 147 & 735 \\
\hline
\end{tabular}

Sumber: Hasil olahan

\section{Metodologi Penelitian}

Penelitian ini menggunakan pendekatan kuantitatif deskriptif dengan data panel atua gabungan antara data time series dan cross section. Karena tujuan dari penelitian ini adalah untuk mengetahui hubungan antara remunerasi direksi dan kinerja keuangan perusahaan, maka variabel dependen yang digunakan adalah kinerja keuangan perusahaan yang diukur dengan menggunakan 
rasio profitabilitas. Menurut Puspitasari dan Budiyanto (2014), pencarian laba atau profit selalu menjadi keinginan mendasar dari kegiatan usaha dan profitabilitas merupakan buah akhir dari tindakan dan keputusan yang perusahaan lakukan. Oleh karena itu, rasio profitabilitas merupakan rasio yang cukup baik dalam mengukur kinerja keuangan perusahaan. Selain itu, laba merupakan salah satu indikator yang baik karena menyatakan keuntungan yang didapatkan perusahaan dan pemberi manfaat kepada investor dan pemegang saham. Rasio profitabilitas yang digunakan untuk mengukur kemampuan perusahaan untuk menghasilkan laba dalam penelitian ini terdiri dari 3 jenis, yaitu margin laba bersih atau profit margin (PM), return on equity (ROE), dan return on assets (ROA) (Krauter, 2013; Ismail et al., 2014).

ROA merupakan alat ukur atau indikator penilaian akan seberapa perusahaan dapat memanfaatkan total aset yang dimiliki perusahaan menjadi laba bersih. ROA memberikan gambaran akan efisiensi perusahaan dalam menggunakan aset perusahaan. Semakin tinggi nilai ROA maka semakin baik untuk perusahaan karena setiap 1 Rupiah aset yang dimiliki perusahaan dapat menghasilkan keuntungan yang semakin besar. Artinya, perusahaan semakin baik dalam mengutilisasi aset yang dimiliki untuk menghasilkan keuntungan. Penulis memiliki asumsi bahwa remunerasi eksekutif mempunyai hubungan positif terhadap kinerja keuangan perusahaan yang ditandai dengan nilai profitabilitas perusahaan, maka diprediksikan jumlah remunerasi eksekutif yang tinggi akan meningkatkan ROA.

ROA dihitung dengan menggunakan rumus sebagai berikut:

$\frac{\text { Laba Bersih Perusa haan }}{\text { Rata-rata Total Aset Perusahaan }} * 100$

ROE merupakan pengukuran dari profitabilitas perusahaaan yang biasanya dipaparkan menggunakan persentase. Nilai ROE merupakan besaran laba perusahaan yang dihasilkan dengan jumlah investasi pemegang saham perusahaan serta modal milik perusahaan sendiri. Secara umum, tingginya nilai ROE mengindikasikan kondisi perusahaan yang semakin baik karena menyatakan perusahaan dapat menghasilkan laba melalui pemanfaatan ekuitas dengan baik. Oleh karena itu, 
penulis memiliki asumsi bahwa remunerasi eksekutif yang semakin tinggi akan menghasilkan nilai ROE yang semakin tinggi pula atau memiliki hubungan yang positif.

ROE memiliki rumus sebagai berikut:

$$
\frac{\text { Laba Bersih Perusahaan }}{\text { Total Ekuitas Perusahaan }} * 100
$$

Penelitian ini juga menggunakan variabel independen yaitu remunerasi eksekutif yang dhihitung sebagai seluruh imbalan yang diterima langsung seperti gaji dan tunjangan-tunjangan eksekutif. Pada laporan keuangan, penerimaan eksekutif terbagi menjadi imbalan kerja jangka pendek, imbalan pascakerja dan imbalan kerja jangka panjang lainnya. Ketiga jenis imbalan kerja tersebut digunakan untuk mencari besaran penerimaan remunerasi eksekutif dalam perusahaan. Seluruh remunerasi yang tercatat dalam laporan keuangan perusahaan akan diambil secara total dan dalam mata uang rupiah. Segala pencatatan dalam mata uang asing dikonversikan berdasarkan nilai tukar yang tercatat dalam laporan keuangan perusahaan pada tahun yang bersangkutan.

Rasio laba bersih (profit margin) mengukur keberhasilan perusahaan dilihat dari laba perusahaan dengan membandingkannya dengan seberapa banyak pendapatan yang dihasilkan. Pendapatan perusahaan tentunya dipengaruhi oleh aktivitas penjualan perusahaan. Nilai PM yang tinggi memberikan arti bahwa tingkat operasional perusahaan semakin efisien. Remunerasi eksekutif dan PM diprediksi untuk memiliki hubungan yang positif.

Rumus dari profit margin adalah sebagai berikut:

$$
\frac{\text { Laba Bersih Perusahaan }}{\text { Penjualan Bersih Perusahaan }} * 100
$$

Variabel kontrol yang digunakan dalam penelitian ini adalah ukuran perusahaan (size), rasio utang (leverage ratio) dan pertumbuhan penjualan (sales growth). Ukuran perusahaan yang digunakan peneliti dicerminkan oleh beberapa komponen keuangan yaitu total aset dan total penjualan yang dimiliki perusahaan dan merupakan salah satu faktor yang berkontribusi besar dalam kinerja keuangan perusahaan (Carpenter dan Sanders, 2002; Cao et al., 2009; Krauter, 2013; Bonsu dan Lutta, 2016; Ogbeide dan Akanji, 2016; Smirnova dan Zavertiaeva, 2017). Rasio utang atau leverage ratio 
yang digunakan adalah debt-to-equity ratio yang mencerminkan kemampuan perusahaan untuk menutupi kewajiban dengan menggunakan ekuitas. Rumus yang digunakan untuk menghitung debtto-equity ratio adalah sebagai berikut:

$$
\frac{D}{E} \text { ratio }=\frac{\text { Total Hutang Perusahaan (Debts) }}{\text { Total Ekuitas Perusahaan }}
$$

Variabel kontrol lainnya yang dapat digunakan adalah pertumbuhan penjualan atau sales growth (Smirnova dan Zavertiaeva, 2017). Variabel ini mengukur nilai perubahan jumlah penjualan perusahaan setiap tahunnya baik nilai tersebut naik maupun turun, dilakukan dengan membandingkan penjualan satu tahun dengan tahun berikutnya dan melihat pertumbuhannya. Berikut merupakan rumus yang digunakan untuk menghitung pertumbuhan penjualan:

$$
\text { Sales Growth }=\frac{\left(\mathrm{TS}_{\mathrm{t}-\mathrm{TS}} \mathrm{t}-1\right)}{\mathrm{TS}_{\mathrm{t}-1}}
$$

Dimana:

$\mathrm{TS}_{\mathrm{t}}=$ Jumlah penjualan pada tahun berjalan

$\mathrm{TS}_{\mathrm{t}-1} \quad=$ Jumlah penjualan pada tahun sebelumnya

\begin{tabular}{|c|c|c|c|c|}
\hline Nama & Kode & Pengukuran & Rumus & $\begin{array}{c}\text { Skala } \\
\text { Pengukura } \\
\text { n }\end{array}$ \\
\hline \multicolumn{5}{|l|}{ Variabel Dependen } \\
\hline Return on Asset & ROA & $\begin{array}{l}\text { Laba bersih dan Total } \\
\text { Aset }\end{array}$ & $\begin{array}{l}\text { (Laba Bersih/ Rata-Rata } \\
\text { Total Aset) x } 100\end{array}$ & Rasio \\
\hline Return on Equity & ROE & $\begin{array}{l}\text { Laba bersih dan Total } \\
\text { Ekuitas }\end{array}$ & $\begin{array}{l}\text { (Laba Bersih/ Total Ekuitas) } \\
\text { x } 100\end{array}$ & Rasio \\
\hline $\begin{array}{lr}\text { Marjin } & \text { Laba } \\
\text { Bersih } & \text { (Profit } \\
\text { Margin) } & \end{array}$ & PM & $\begin{array}{l}\text { Laba bersih dan Total } \\
\text { Penjualan }\end{array}$ & $\begin{array}{l}\text { (Laba Bersih/ Penjualan } \\
\text { Bersih) x } 100\end{array}$ & Rasio \\
\hline
\end{tabular}

Tabel 1. Ringkas an Variabel 


\begin{tabular}{|c|c|c|c|c|}
\hline \multicolumn{5}{|c|}{ Variabel Independen } \\
\hline $\begin{array}{l}\text { Remunerasi } \\
\text { Eksekutif }\end{array}$ & $\begin{array}{l}\text { LOG } \\
\text { COMP }\end{array}$ & $\begin{array}{l}\text { Imbalan Kerja Jangka } \\
\text { Pendek, Imbalan Pasca } \\
\text { Kerja, dan Imbalan } \\
\text { Kerja Panjang Lainnya }\end{array}$ & $\begin{array}{l}\text { Log (Imbalan kerja jangka } \\
\text { pendek + Imbalan pasca kerja } \\
+ \text { Imbalan kerja jangka } \\
\text { panjang lainnya) }\end{array}$ & Rasio \\
\hline \multicolumn{5}{|l|}{ Variabel Kontrol } \\
\hline $\begin{array}{l}\text { Ukuran } \\
\text { Perusahaan }\end{array}$ & $\begin{array}{l}\text { LOGT } \\
\text { A }\end{array}$ & Total Aset & Log (Total Aset) & Rasio \\
\hline Rasio Utang & LR & Debt-to-Equity Ratio & $\begin{array}{l}\text { Total Hutang (Debts)/Total } \\
\text { Ekuitas }\end{array}$ & Rasio \\
\hline $\begin{array}{l}\text { Pertumbuhan } \\
\text { Penjualan (Sales } \\
\text { Growth) }\end{array}$ & SG & Jumlah Penjualan & $\begin{array}{l}\left(\text { Penjualan }_{t}-\text { Penjualan }_{t-1}\right) / \\
\text { Penjualan }_{t-1}\end{array}$ & Rasio \\
\hline
\end{tabular}

\section{Sumber : Olahan Penulis}

Pada penelitian ini, metode utama yang dipakai penulis adalah regresi linear dengan menggunakan data panel. Regresi data panel dilakukan setelah mengetahui model estimasi yang tepat apakah common effects, fixed effects, atau random effects dengan menggunakan uji Chow, uji Hausman dan uji Lagrange Multiplier (LM). Uji asumsi klasik juga dilakukan untuk mengetahui adanya bias pada data penelitian, yang terdiri dari beberapa uji yakni uji normalitas, uji autokorelasi, uji multikolinearitas, dan uji heteroskedastisitas.

Selain itu, penulis juga melakukan uji F-statistik dan regresi untuk mengetahui hubungan antara melihat hubungan antara variabel independen terhadap variabel dependen penelitian. Uji koefisien determinasi dilakukan untuk mengetahui seberapa besar variasi pada variabel dependen dapat dije laskan oleh variasi pada variabel independen dan variabel kontrol.

\section{Hasil dan Diskusi}




\section{Analis is Deskriptif Statistik}

Tabel 3. Has il Analisa Deskriptif Statistik

\begin{tabular}{|c|c|c|c|c|c|c|c|}
\hline & ROA & ROE & PM & COMP & TA & LR & SG \\
\hline Mean & 4.1455 & 8.8281 & 44.3024 & 31300000 & 31319473 & 82.4690 & 13.0631 \\
\hline Med & 2.5734 & 8.7442 & 6.5957 & 13400000 & 6567267 & 49.8522 & 7.3692 \\
\hline Max & 85.0533 & 157.7816 & 17933 & 56300000 & 1120000 & 1134.314 & 843.2627 \\
\hline Min & -26.2115 & -100.024 & -519.272 & 18200000 & 73912.75 & 0.0000 & -87.124 \\
\hline Std. Dev. & 8.2397 & 21.8851 & 693.794 & 51200000 & 96759803 & 119.7753 & 55.8973 \\
\hline Ske wness & 2.6183 & 0.9839 & 23.8081 & 4.78594 & 7.4080 & 4.0953 & 9.924 \\
\hline Kurtos is & 19.9620 & 16.0400 & 605.5388 & 35.59928 & 68.4055 & 26.6095 & 134.8005 \\
\hline Jarq. Bera & 9650.336 & 5326.059 & 11187934 & 35351.47 & 137732.7 & 19125.07 & 544062.7 \\
\hline Prob. & 0.0000 & 0.0000 & 0.0000 & 0.0000 & 0.0000 & 0.0000 & 0.0000 \\
\hline Obs. & 735 & 735 & 735 & 735 & 735 & 735 & 735 \\
\hline \multicolumn{8}{|c|}{ Keterangan: } \\
\hline \multicolumn{8}{|c|}{$\begin{array}{l}\text { ROA adalah return on asset; ROE adalah return on equity; PM adalah marjin laba bersih ( } \text { profit } \\
\text { margin); COMP adalah remunerasi eksekutif; TA adalah total aset atau ukuran perusahaan; LR } \\
\text { adalah rasio utang; SG adalah pertumbuhan penjualan (sales growth) }\end{array}$} \\
\hline
\end{tabular}

Sumber: Hasil pengolahan data - Eviews

Tabel 3 menunjukkan hasil deskriptif statistik dari seluruh variabel yang dipakai dalam penelitian. Remunerasi memiliki nilai tertinggi sebesar Rp 563 milyar dan terendah sebesar Rp 182 juta dengan nilai rata-rata berada pada angka sebesar Rp 31.3 milyar. Nilai ROA tertinggi berada di angka 85.053 dan terendah yaitu sebesar -26.212 , sedangkan variabel ROE mempunyai nilai tertinggi sebesar 157.782 dan nilai terendah sebesar -100.024. Variabel PM tertinggi sebesar 17,933 dengan nilai terendah berada pada nilai -519.272 .

\section{Hasil Uji Estimasi Model}

Hasil uji Chow menghasilkan bahwa ketiga model persamaan untuk variabel dependen Profit Margin, ROA, dan ROE, memiliki model fixed effect karena nilai cross-section F berada di bawah 
0.05. Selanjutnya, dilakukan uji Hausman dan didapatkan hasil yang serupa untuk ROA, ROE yaitu fixed effects. Namun untuk persamaan model Profit Margin adalah random effect. Pada uji terakhir yaitu uji Lagrange Multiplier (LM), seluruh variabel baik ROA, ROE, dan PM memilki estimasi model random effect. Kesimpulan dari uji estimasi model ini adalah ROA, ROE, dan PM mengikuti model random effect.

\section{Hasil Uji Korelasi}

Berdasarkan hasil uji korelasi yang dapat dilihat di tabel 4, hubungan antara variabel dependen dan independen paling kuat terdapat pada LOGCOMP dan ROE yaitu sebesar 0.2209, diikuti dengan LOGCOMP dengan ROA sebesar 0.1589. Hubungan antara LOGCOMP dan PM yang memiliki nilai negatif mencerminkan bahwa kedua variabel tidak memiliki hubungan yang erat maka pemberian kompensasi yang semakin tinggi akan membuat PM perusahaan menurun. Dengan demikian, adanya korelasi positif LOGCOMP terhadap variabel dependen menyatakan bahwa ada hubungan positif antara variabel tersebut.

Tabel 4. Hasil Uji Korelasi

\begin{tabular}{|c|c|c|c|c|c|}
\hline \multicolumn{6}{|c|}{ Variabel Dependen : ROA } \\
\hline & ROA & LOGCOMP & LOGTA & LR & SG \\
\hline ROA & 1.0000 & & & & \\
\hline LOGCOMP & $0.1589 *$ & 1.0000 & & & \\
\hline LOGTA & -0.0301 & $0.7468 *$ & 1.0000 & & \\
\hline $\mathbf{L R}$ & $-0.2110 *$ & -0.0091 & $0.1001 *$ & 1.0000 & \\
\hline SG & $0.1253 *$ & $-0.0697 *$ & -0.0184 & -0.0413 & 1.0000 \\
\hline \multicolumn{6}{|c|}{ Variabel Dependen : ROE } \\
\hline & ROE & $\mid$ LOGCOMP & LOGTA & $\mathbf{L R}$ & SG \\
\hline ROE & 1.0000 & & & & \\
\hline LOGCOMP & $0.2209^{*}$ & 1.0000 & & & \\
\hline LOGTA & $0.0727 *$ & $0.7468 *$ & 1.0000 & & \\
\hline $\mathbf{L R}$ & $-0.1244^{*}$ & -0.0091 & $0.1001 *$ & 1.0000 & \\
\hline SG & $0.1307 *$ & $-0.0697 *$ & -0.0184 & -0.0413 & 1.0000 \\
\hline
\end{tabular}




\begin{tabular}{|l|c|c|c|c|c|}
\hline & PM & LOGCOMP & LOGTA & LR & SG \\
\hline PM & 1.0000 & & & & \\
\hline LOGCOMP & $-0.0614^{*}$ & 1.0000 & & & \\
\hline LOGTA & 0.0093 & $0.7468^{*}$ & 1.0000 & & \\
\hline LR & -0.0419 & -0.0091 & $0.1001 *$ & 1.0000 & \\
\hline SG & 0.0129 & $-0.0697^{*}$ & -0.0184 & -0.0413 & 1.0000 \\
\hline
\end{tabular}

Kete rangan:

ROA adalah return on asset; ROE adalah return on equity; PM adalah marjin laba bersih (profit margin); LOGCOMP adalah logaritma dari remunerasi eksekutif; LOGTA adalah logaritma dari total aset atau ukuran perusahaan; LR adalah rasio utang; SG adalah pertumbuhan penjualan (sales growth)

* = Signifikan dengan nilai korelasi $>0.05$

Sumber: Hasil pengolahan data - Eviews

\section{Hasil Uji Hipotes is (Uji-F dan Uji-t)}

Uji Hipotesis dengan metode regresi data panel dilakukan setelah melakukan uji asumsi klasik untuk memastikan bahwa parameter yang dihasilkan dalam uji regresi merupakan BLUE (Best Linear Unbiasssed Estimator). Berdasarkan hasil uji asumsi klasik terdapat beberapa pelanggaran untuk asumsi autokorelasi dan heteroskedatisitas pada model ROA, ROE dan PM sehingga digunakan metode Generalized Least Squares (GLS). Hipotesis yang akan diuji dalam penelitian ini adalah apakah remunerasi direksi berpengaruh positif terhadap kinerja keuangan perusahaan.

Tabel 5. Hasil Regresi

\begin{tabular}{|c|c|c|c|c|c|c|c|c|c|}
\hline \multirow[b]{2}{*}{ Variabel } & \multicolumn{3}{|c|}{ ROA (GLS) } & \multicolumn{3}{|c|}{ ROE(GLS) } & \multicolumn{3}{|c|}{ PM (GLS) } \\
\hline & Coef. & $\begin{array}{l}\text { Std. } \\
\text { Error }\end{array}$ & Prob & Coef. & $\begin{array}{l}\text { Std. } \\
\text { Error }\end{array}$ & Prob & Coef. & $\begin{array}{l}\text { Std. } \\
\text { Error }\end{array}$ & Prob \\
\hline (Constant) & -22.7338 & 8.5637 & $0.0081 * * *$ & -83.6481 & 23.1924 & $0.0003 * * *$ & 1594.8630 & 662.4003 & $0.0163^{* *}$ \\
\hline LOGCOMP & 4.2871 & 1.1374 & $0.0002 * * *$ & 11.4963 & 3.0672 & $0.0002 * * *$ & -243.0842 & 90.3520 & $0.0073 * * *$ \\
\hline LOGTA & -1.7300 & 0.9122 & $0.0583^{*}$ & $\mid-1.9767$ & 2.4783 & 0.4254 & 160.3520 & 69.0094 & $0.0204 * *$ \\
\hline$L R$ & -0.0136 & 0.0031 & $0.0000 * * *$ & -0.0256 & 0.0083 & $0.0021 * * *$ & -0.3175 & 0.2626 & 0.2270 \\
\hline$S G$ & 0.0207 & 0.0039 & $0.0000^{*} * *$ & 0.0502 & 0.0101 & $0.0000^{* * *}$ & -0.6226 & 0.4149 & 0.1339 \\
\hline Year & -0.5403 & 0.1440 & $0.0002^{*} * *$ & -1.4382 & 0.3777 & $0.0002 * * *$ & -16.6552 & 15.6330 & 0.2871 \\
\hline
\end{tabular}




\begin{tabular}{|c|c|c|c|}
\hline Sector & $\mid \begin{array}{lll}-0.4760 & 0.1977 & 0.0163^{* *}\end{array}$ & $\mid \begin{array}{lll}-1.0492 & 0.5423 & 0.0534^{*}\end{array}$ & |-17.3276 $13.9917 \quad 0.2160$ \\
\hline $\mathrm{R}^{2}$ & 0.1079 & 0.0890 & 0.0155 \\
\hline Adj. $R^{2}$ & 0.1005 & 0.0815 & 0.0074 \\
\hline F-Stats & 14.6688 & 11.8510 & 1.9059 \\
\hline Prob. (F-Stat.) & $\mathbf{0 . 0 0 0 0} * * *$ & $0.0000 * * *$ & $0.0000 * * *$ \\
\hline \multicolumn{4}{|l|}{ Keterangan: } \\
\hline \multirow{3}{*}{\multicolumn{4}{|c|}{$\begin{array}{l}\text { ROA adalah return on asset; ROE adalah return on equity; PM adalah marjin laba bersih (profit margin); } \\
\text { LOGCOMP adalah logarit ma dari remunerasi eksekutif; LOGTA adalah logarit ma dari total aset atau ukuran } \\
\text { perusahaan; LR adalah rasio utang; SG adalah pertu mbuhan penjualan (sales growth) }\end{array}$}} \\
\hline & & & \\
\hline & & & \\
\hline \multicolumn{4}{|c|}{$* \quad$ : Signifikan dengan nilai $p$-value $<0.1$} \\
\hline \multicolumn{4}{|c|}{$* *$ : Signifikan dengan nilai $\mathrm{p}$-value $<0.05$} \\
\hline \multicolumn{4}{|c|}{$* * *$ : Signifikan dengan nilai $p$-value $<0.01$} \\
\hline
\end{tabular}

Sumber: Hasil pengolahan data - Eviews

Hasil uji-F pada penelitian ini dapat dilihat dari tabel di atas dimana terdapat nilai $\mathrm{F}_{\text {hitung }}$ sebesar 14.6688, 11.8510, dan 1.9059 untuk ROA, ROE, dan PM secara berturut-turut dan probabilitas F-statistik untuk ROA, ROE adalah sebesar 0.000 sedangkan untuk PM sebesar 0.0774. $\mathrm{F}_{\text {tabel }}$ yang didapatkan untuk model penelitian ini adalah sebesar 2.67. Dengan hasil tersebut, dimana $\mathrm{F}_{\text {hitung }}$ lebih tinggi dari $\mathrm{F}_{\text {tabel }}$ dan nilai probabilitas $\mathrm{F}$ lebih rendah dari level signifikansi (5\%), maka penulis dapat menarik kesimpulan untuk menermia $\mathrm{H}_{1}$ yaitu variabel independen penelitian secara bersama-sama memiliki pengaruh terhadap variabel dependen ROA dan variabel dependen ROE.

Hasil Uji-t pada penelitian ini dapat dilihat di Tabel 4. Hasil ROA terhadap seluruh variabel independen mempunyai t-hitung yang lebih tingi dari t-tabel dan probabilitas yang berada di bawah nilai alpha sehingga dapat memberikan kesimpulan untuk menolak $\mathrm{H}_{0}$ atau variabel independen memiliki pengaruh signifikan terhadap ROA.

Berbeda dengan hasil yang didapatkan ROA, ROE menunjukkan hasil uji-t dimana variabel independen tertentu yakni LOGCOMP, SG, dan LR memiliki pengaruh sangat signifikan terhadap 
ROE dan TA memiliki pengaruh signifikan terhadap ROE dengan nilai signifikansi yang lebih kecil dari 3 variabel lainnya.

Hasil yang diberikan dengan variabel dependen PM berbeda dengan hasil ROA dan ROE. Pada hasil uji-t dengan PM, variabel independen LOGCOMP, LOGTA, dan LR tidak memiliki pengaruh signifikan terhadap PM sedangkan SG ditemukan bahwa mempunyai pengaruh signifikan terhadap PM.

\section{Uji Koefisien Determinasi $\left(\mathbf{R}^{2}\right)$}

Hasil regresi di Tabel 4 menunjukan nilai adjusted $R^{2}$ sebesar $10.05 \%$ untuk model penelitian dimana ROA sebagai variabel dependen, $8.15 \%$ pada model yang menggunakan variabel dependen ROE, dan $0.74 \%$ untuk penggunaan PM menjadi variabel dependennya. Angka tersebut menjelaskan mengenai besaran kontribusi antara variabel independen penelitian dan setiap variabel dependen sebagai indikator kinerja keuangan perusahaan (ROA, ROE, dan PM). Oleh karena itu, dapat dikatakan bahwa variasi variabel independen dalam model ROA, ROE, dan PM dapat menjelaskan sebesar $10.05 \%, 8.15 \%$ dan $0.74 \%$ dari variasi ROA, ROE dan PM secara berutan.

Hubungan positif antara LOGCOMP terhadap ROA dan ROE ditemukan dengan koefisien sebesar 4.287 dan 11.496, hubungan positif terhadap ROA dan ROE juga ditemukan pada variabel independen SG. Namun, hubungan negatif ditemukan pada variabel LOGTA, LR, dan variabel dummy yakni tahun dan sektor. Hasil yang berbeda ditemukan pada variabel PM dengan LOGCOMP yang memiliki hasil yang signifikan namun memiliki koefisien negatif yakni sebesar 243.084 Hubungan negatif juga ditemukan pada seluruh variabel independen yang digunakkan kecuali LOGTA. variabel LOGTA memiliki hubungan positif dengan PM namun tidak signifikan dengan probabilitas sebesar 0.0204 .

\section{Uji Robustness}

Penulis kemudian melakukan uji robustness dimana pada uji ini terdapat dua model la in yang ditambahkan dan menghilangkan outlier pada data yang penulis gunakan. Uji robustness pertama 
dilakukan untuk membuktikan apakah ada faktor lain yang mempengaruhi variabel pada penelitian dan menguji tingkat normalitas data. Persamaan untuk 2 model tambahan yang dimaksud adalah:

$\mathrm{Y}=\mathrm{a}+\beta 1 \mathrm{LOGCOMP}+\beta_{2} \mathrm{LOGTA}+\beta_{3} \mathrm{SG}+\beta_{4} \mathrm{LR}+\beta_{5} \mathrm{UD}$

$\mathrm{Y}=\mathrm{a}+\beta_{1} \mathrm{COMP} \_\mathrm{DIR}+\beta_{2} \mathrm{LOGTA}+\beta_{3} \mathrm{SG}+\beta_{4} \mathrm{LR}$

Dimana:

$\mathrm{UD}=$ ukuran dewan atau board size

LOGCOMP_DIR = jumlah remunerasi per jumlah direksi

Pengujian robustness pertama dilakukan penulis untuk mengetahui apakah ukuran dewan direksi benar dapat mempengaruhi variabel pada penelitian serta mengetahui besaran pengaruh yang diberikan kepada variabel penelitian. Selain itu pada uji robustness kedua, penulis juga ingin melihat perubahan yang terjadi jika variabel remunerasi diubah menjadi LOGCOMP_DIR yakni perkiraan jumlah remunerasi yang didapatkan oleh satu direksi di setiap perusahaan, dengan asumsi seluruh direksi mendapatkan jumlah remunerasi yang sama.

Uji robustness ketiga dilakukan dengan menghilangkan nilai outlier yaitu data yang memiliki nilai sebesar kurang dari dan lebih dari 3 standar deviasi untuk melihat apakah signifikansi dan model penelitian akan lebih baik jika data tersebut dihilangkan. Pengurangan data juga dilaksanakan untuk melihat tingkat normalitas data tanpa adanya outlier.

Uji Robustness - 1

Tabel 6. Hasil Uji Robustness 1

\begin{tabular}{|c|c|c|c|c|c|c|c|c|c|}
\hline \multirow[b]{2}{*}{ Variabel } & \multicolumn{3}{|c|}{ ROA (GLS) } & \multicolumn{3}{|c|}{ ROE (GLS) } & \multicolumn{3}{|c|}{ PM (OLS) } \\
\hline & Coef. & $\begin{array}{l}\text { Std. } \\
\text { Error }\end{array}$ & Prob & Coef. & $\begin{array}{l}\text { Std. } \\
\text { Error }\end{array}$ & Prob & Coef. & $\begin{array}{l}\text { Std. } \\
\text { Error }\end{array}$ & Prob \\
\hline (Constant) & -27.9645 & 9.2328 & $0.0025^{* * *}$ & -98.0644 & 24.9935 & $0.0001 * * *$ & 1177.0590 & 723.7820 & 0.1043 \\
\hline LOGCOMP & 4.6884 & 1.1683 & $0.0001 * * *$ & 12.6019 & 3.1532 & $0.0001 * * *$ & -212.2068 & 92.9691 & $0.0227 * *$ \\
\hline LOGTA & -1.2611 & 0.9631 & 0.1908 & -0.6849 & 2.6137 & 0.7934 & 200.5374 & 74.4901 & $0.0073 * * *$ \\
\hline$L R$ & -0.0136 & 0.0031 & $0.0000 * * *$ & -0.0258 & 0.0083 & $0.0020 * * *$ & -0.3328 & 0.2630 & 0.2063 \\
\hline
\end{tabular}




\begin{tabular}{|c|c|c|c|c|c|c|c|c|}
\hline$S G$ & 0.0209 & $0.00390 .0000^{* * *}$ & 0.0506 & 0.0101 & $0.0000 * * *$ & $\mid-0.6147$ & 0.4148 & 0.1388 \\
\hline$U D$ & -0.3548 & 0.23300 .1282 & -0.9768 & 0.6226 & 0.1171 & -29.0062 & 20.0919 & 0.1493 \\
\hline Year & -0.5714 & $0.14540 .0001 * * *$ & -1.5240 & 0.3816 & $0.0001 * * *$ & -19.2183 & 15.7253 & 0.2221 \\
\hline Sector & -0.4850 & $0.19800 .0145^{* *}$ & -1.0736 & 0.5439 & $0.0488 * *$ & -18.3552 & 14.0329 & 0.1913 \\
\hline $\mathbf{R}^{2}$ & & 0.1107 & & & 0.0920 & & & 0.0182 \\
\hline Adj. $\mathbf{R}^{2}$ & & 0.1021 & & & 0.0832 & & & 0.0088 \\
\hline F-Stats & & 12.9237 & & & 10.5211 & & & 1.9265 \\
\hline \multirow{5}{*}{\multicolumn{9}{|c|}{$\begin{array}{l}\text { Keterangan: } \\
\text { ROA adalah return on asset; ROE adalah return on equity; PM adalah marjin laba bersih (profit margin); } \\
\text { LOGCOMP adalah logaritma dari remunerasi eksekutif; LOGTA adalah logarit ma dari total aset atau ukuran } \\
\text { perusahaan; LR adalah rasio utang; SGadalah pertu mbuhan penjualan (sales growth); UD adalah ukuran dewan } \\
\text { (board size). }\end{array}$}} \\
\hline & & & & & & & & \\
\hline & & & & & & & & \\
\hline & & & & & & & & \\
\hline & & & & & & & & \\
\hline \multicolumn{9}{|c|}{ * : Signifikan dengan nilai p-value $<0.1$} \\
\hline \multicolumn{9}{|c|}{$* *$ : Signifikan dengan nilai $\mathrm{p}$-value $<0.05$} \\
\hline \multicolumn{9}{|c|}{$* * *$ : Signifikan dengan nilai $p$-value $<0.01$} \\
\hline
\end{tabular}

Sumber: Hasil pengolahan data - Eviews

Terdapat beberapa penelitian yang menggunakan ukuran dewan sebagai variabel kontrol seperti Cao et al. (2009), Smirnova dan Zavertiaeva (2017), serta Ogbeide dan Akanji (2016). Cao et al. (2009) dan Ogbeide dan Akanji (2016) tidak menemukan hubungan ukuran dewan dengan kinerja perusahaan.

Pada hasil yang ditampilkan oleh tabel 6, adanya penambahan ukuran dewan (UD) sebagai variabel kontrol pada penelitian yang dilakukan penulis tidak memberikan pengaruh yang signifikan pada ketiga dependen variabel. Seluruh probabilitas untuk UD lebih besar dari 0.05 pada setiap model. Penambahan variabel kontrol ini memang membuat nilai signifikansi dari remunerasi Direksi semakin kecil atau semakin signifikan terhadap dependen variabel namun nilai dari adjusted $\mathrm{R}^{2}$ pada model dengan penambahan UD sebagai kontrol variabel memiliki besaran yang kurang lebih sama dengan pada model awal penelitian.

Uji Robustness -2 
Tabel 7. Hasil Uji Robustness 2

\begin{tabular}{|c|c|c|c|c|c|c|c|c|c|}
\hline \multirow[b]{2}{*}{ Variabel } & \multicolumn{3}{|c|}{ ROA (GLS) } & \multicolumn{3}{|c|}{ ROE (GLS) } & \multicolumn{3}{|c|}{ PM (OLS) } \\
\hline & Coef. & $\begin{array}{c}\text { Std. } \\
\text { Error }\end{array}$ & Prob & Coef. & $\begin{array}{c}\text { Std. } \\
\text { Error }\end{array}$ & Prob & Coef. & $\begin{array}{c}\text { Std. } \\
\text { Error }\end{array}$ & Prob \\
\hline (Constant) & 10.0518 & 4.7758 & $0.0357 * *$ & 2.5346 & 13.0872 & 0.8465 & -91.1716 & 344.1071 & 0.7911 \\
\hline COMP_DIR & 0.0000 & 0.0000 & $0.0032 * * *$ & 0.0000 & 0.0000 & $0.0097 * * *$ & 0.0000 & 0.0000 & 0.4568 \\
\hline LOGTA & -0.1985 & 0.7347 & 0.7871 & 2.4433 & 2.0105 & 0.2247 & 42.3384 & 53.4984 & 0.4290 \\
\hline$L R$ & -0.0143 & 0.0031 & $0.0000 * * *$ & -0.0280 & 0.0084 & $0.0009 * * *$ & -0.2486 & 0.2628 & 0.3444 \\
\hline$S G$ & 0.0205 & 0.0039 & $0.0000 * * *$ & 0.0493 & 0.0101 & $0.0000 * * *$ & -0.5745 & 0.4153 & 0.1670 \\
\hline Year & -0.5340 & 0.1439 & $0.0002 * * *$ & -1.4192 & 0.3780 & $0.0002 * * *$ & -17.3343 & 15.6608 & 0.2687 \\
\hline Sector & -0.5688 & 0.2015 & $0.0049 * * *$ & -1.3077 & 0.5552 & $0.0188 * *$ & -11.4011 & 13.8760 & 0.4115 \\
\hline $\mathbf{R}^{2}$ & 0.1013 & & & 0.0803 & & & 0.0067 & & \\
\hline Adj. $R^{2}$ & 0.0939 & & & 0.0727 & & & -0.0015 & & \\
\hline F-S tats & 13.6829 & & & 10.5929 & & & 0.08164 & & \\
\hline \multicolumn{10}{|c|}{$\begin{array}{l}\text { Keterangan: } \\
\text { ROA adalah return on asset; ROE adalah return on equity; PM adalah marjin laba bersih (profit margin); COMP_DIR adalah } \\
\text { remunerasi per direksi; LOGTA adalah logaritma dari total aset atau ukuran perusahaan; LR adalah rasio utang; SG adalah } \\
\text { pertumbuhan penjualan (sales growth) }\end{array}$} \\
\hline $\begin{array}{l}* \text { : Signifikan } \\
* * \text { : Signifikan } \\
\text { ***: Signifikan }\end{array}$ & $\begin{array}{l}\mathrm{n} \text { nilai } \mathrm{p}- \\
\mathrm{n} \text { nilai } \mathrm{p}- \\
\text { an nilai } \mathrm{p}\end{array}$ & $\begin{array}{l}\text { alue }<0 . \\
\text { alue }<0 . \\
\text { value }<0\end{array}$ & & & & & & & \\
\hline
\end{tabular}

Sumber: Hasil pengolahan data - Eviews

Tabel 7 menunjukan Hasil Uji Robustness 2 yang dilakukan dengan mengganti variabel COMP menjadi COMP_DIR atau remunerasi per direksi. Hasilnya menunjukan bahwa nilai probabilitas menjadi lebih besar menjadi 0.0032, 0.0097 dan 0,4568 untuk ROA, ROE, dan PM secara berurutan. Angka ini menunjukkan bahwa pemberian remunerasi per Direksi semakin tidak signifikan, terlebih kepada PM.

Meskipun begitu, besaran angka dari koefisien COMP_DIR masih mencerminkan adanya pengaruh positif antara remunerasi Direksi dengan kinerja keuangan perusahaan. Uji Robustness-2 ini 


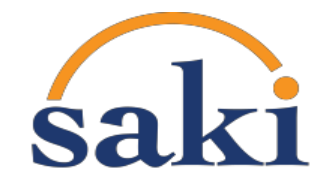

membuktikan bahwa besaran pemberian remunerasi dengan besaran yang lebih seimbang untuk setiap direksi mempengaruhi kinerja keuangan perusahan.

\section{Uji Robustness -3}

Pada robustness 3, penulis bermaksud untuk menghilangkan outlier yang ada pada data penelitian awal dimana range digunakan adalah sebesar 3 standar deviasi. Setelah outlier data dihilangkan, maka jumlah data untuk setiap komponen kinerja keuangan perusahaan adalah 700 data dengan 140 perusahaan, 700 data dengan 140 perusahaan dan 730 data dengan 146 perusahaan untuk ROA, ROE, dan PM secara berurutan.

Tabel 8. Hasil Uji Regresi Robustness 3

\begin{tabular}{|c|c|c|c|c|c|c|c|c|c|}
\hline \multirow[b]{2}{*}{ Variabel } & \multicolumn{3}{|c|}{ ROA (GLS) } & \multicolumn{3}{|c|}{ ROE (GLS) } & \multicolumn{3}{|c|}{ PM (OLS) } \\
\hline & Coef. & $\begin{array}{c}\text { Std. } \\
\text { Error }\end{array}$ & Prob & Coef. & $\begin{array}{c}\text { Std. } \\
\text { Error }\end{array}$ & Prob & Coef. & $\begin{array}{c}\text { Std. } \\
\text { Error }\end{array}$ & Prob \\
\hline (Constant) & -10.1104 & 6.3117 & 0.1096 & -43.6305 & 16.0301 & $0.0067 * * *$ & -171.0423 & 78.6402 & $0.03 * *$ \\
\hline LOGCOMP & 2.4858 & 0.8398 & $0.0032 * * *$ & 6.2515 & 2.1365 & $0.0035^{* * *}$ & 21.1106 & 10.7615 & $0.0502 *$ \\
\hline LOGTA & -1.1874 & 0.6635 & $0.0740^{*}$ & -0.6718 & 1.7001 & 0.6929 & -5.6294 & 8.1786 & 0.4915 \\
\hline$L R$ & -0.0096 & 0.0023 & $0.0000^{* * *}$ & -0.0333 & 0.0073 & $0.0000 * * *$ & -0.028278 & 0.0308 & 0.3581 \\
\hline$S G$ & 0.0168 & 0.0028 & $0.0000^{* * *}$ & 0.0382 & 0.0071 & $0.0000 * * *$ & 0.116613 & 0.0502 & $0.0203 * *$ \\
\hline Year & -0.4135 & 0.1055 & $0.0001 * * *$ & -1.5697 & 0.2716 & $0.0000 * * *$ & -3.1336 & 1.8245 & $0.0863^{*}$ \\
\hline Sector & -0.3660 & 0.1489 & $0.0142 * *$ & -0.3429 & 0.3785 & 0.3652 & 1.6123 & 1.6476 & 0.3281 \\
\hline $\mathbf{R}^{2}$ & 0.1134 & & & 0.1168 & & & 0.0204 & & \\
\hline Adj. $\mathbf{R}^{2}$ & 0.1058 & & & 0.1092 & & & 0.0122 & & \\
\hline F-S tats & 14.779 & & & 15.2813 & & & 2.5041 & & \\
\hline \multirow{3}{*}{\multicolumn{10}{|c|}{$\begin{array}{l}\text { Keterangan: } \\
\text { ROA adalah return on asset; ROE adalah return on equity; PM adalah marjin laba bersih (profit margin); LOGCOMP adalah } \\
\text { logaritma dari remunerasi eksekutif; LOGTA adalah logaritma dari total aset atau ukuran perusahaan; LR adalah rasio utang; }\end{array}$}} \\
\hline & & & & & & & & & \\
\hline & & & & & & & & & \\
\hline \multicolumn{10}{|c|}{ SG adalah pertumbuhan penjualan (sales growth) } \\
\hline \multicolumn{10}{|c|}{$* \quad$ : Signifikan den gan nilai $\mathrm{p}$-value $<0.1$} \\
\hline \multicolumn{10}{|c|}{$* *$ : Signifikan den gan nilai $\mathrm{p}$-value $<0.05$} \\
\hline$* * *:$ Signifika & ngan nilai & -value $<$ & 0.01 & & & & & & \\
\hline
\end{tabular}

Sumber: Hasil pengolahan data - Eviews 
Dari hasil pengujian yang telah dilakukan, terlihat bahwa total pemberian remunerasi kepada Direksi perusahaan memiliki pengaruh yang signifikan pada ROA dan ROE yaitu sebesar 0.0032 dan 0.0035 meskipun nilai probabilitasnya lebih besar dari nilai signifikansi pada regresi data penuh. Sama seperti dengan hasil penelitian awal penulis, pemberian remunerasi Direksi memiliki pengaruh pada PM perusahaan namun nilai signifikansinya adalah sebesar 0.0502 dimana nilai ini jauh lebih besar dari hasil regresi dengan data penuh.

\section{Kesimpulan, Implikasi, dan Keterbatasan}

Hasil penelitian yang dilakukan penulis sesuai dengan hipotesis penulis dimana remunerasi direksi memiliki hubungan positif signifikan terhadap kinerja keuangan perusahaan, hasil ini sejalan dengan penelitian Carpenter dan Sanders (2002), Kube (2008), Cao et al. (2009), Krauter (2013), Ismail et al. (2014), Muller (2014), Subekti dan Sumargo (2015), serta Smirnova dan Zavertiaeva (2017). Kinerja keuangan perusahaan dinilai dengan menggunakan tiga komponen yakni Return On Assets (ROA), Return On Equity (ROE) dan Profit Margin (PM) sebagai variabel dependen, satu independen utama penelitian yaitu remunerasi dan tiga variabel kontrol penelitian yaitu Total Asset $(T A)$, Leverage Ratio $(L R)$ dan Sales Growth $(S G)$ atau pertumbuhan penjualan. Penelitian ini menggunakan sampel sebanyak 147 perusahaan yang tercatat pada Bursa Efek Indonesia (BEI) dengan total data sebanyak 735 tahun perusahaan dalam jangka waktu dari tahun 2013 sampai 2017.

Peneliti menemukan bahwa ada hubungan positif antara remunerasi direksi terhadap ROA dan ROE dimana semakin tinggi pemberian remunerasi kepada direksi perusahaan akan membuat ROA dan ROE dari perusahaan yang bersangkutan meningkat. Pemberian remunerasi direksi benar dapat dijadikan insentif untuk meningkatkan kinerja perusahaan. Maka hipotesis penelitian untuk kinerja keuangan ROA dan ROE diterima.

Namun, hasil yang berbeda didapatkan pada penggunaan PM, yaitu ditemukan adanya hubungan negatif antara remunerasi direksi terhadap PM sebagai variabel dependen, sehingga remunerasi direksi dan PM memiliki hubungan yang tidak searah dimana pemberian remunerasi 
direksi yang semakin tinggi membuat profit margin dari perusahaan menurun atau sebaliknya. Hal ini secara statistik dapat disebabkan karena data PM yang digunakan memiliki distribusi yang lebih tidak normal jika dibandingkan dengan normalitas ROA dan ROE. Hal tersebut dapat juga dilihat dari besaran angka pada nilai minimum dan maksimum dari PM yang memiliki range sangat tinggi.

Peneliti telah membuktikan bahwa ada pengaruh pemberian remunerasi direksi terhadap kinerja keuangan perusahaan. Pemberian remunerasi dengan jumlah yang sesuai memotivasi direksi untuk bekerja lebih baik, yang nantinya dapat meningkatkan performa keuangan perusahaan.

Penulis ingin menarik beberapa keterbatasan dalam penelitian ini serta memberikan saran untuk penelitian selanjutnya agar penelitian ini dapat diperluas kembali. Adapun keterbatasan dan saran yang penulis dapat berikan adalah sebagai berikut:

1. Penelitian ini menggunakan pengambilan data remunerasi direksi secara manual yang mengandung resiko human error.

2. Peneliti tidak menggunakan komponen kepemilikan saham manajerial pada penelitian ini

3. Peneliti menggunakan periode penelitian yang dapat digolongkan terlalu pendek sehingga untuk peneliti selanjutnya dapat memperpanjang periode penelitian menjadi lebih dari 5 tahun.

4. Penelitian selanjutnya dapat meneliti pengaruh pemberian remunerasi direksi di suatu periode waktu tertentu terhadap kinerja keuangan perusahaan di periode waktu yang berbeda.

5. Variabel kontrol yang digunakan peneliti merujuk pada penelitian-penelitian sebelumnya, dengan begitu untuk peneliti selanjutnya, variabel kontrol dapat diperbanyak dan diperluas. 


\section{Referensi}

Anggriawan, K. H., Hamid D. \& Mukzam, M. D. 2015. 'Pengaruh Insentif dan Motivasi Terhadap Kinerja Karyawan'. Jurnal Administrasi Bisnis. Vol. 28, No. 1.

Balafas, N. \& Florackis, C. 2014. 'CEO Compensation and Future Shareholder Returns: Evidence from the London Stock Exchange'. Journal of Empirical Finance. Vol 27, hh. 97-115.

Balsam, S. 2002. An Introduction to Executive Compensation. Amerika: Academic Press.

Becker, G. S. 1962. 'Investment in Human Capital: A Theoretical Analysis'. Journal of Political Economy. Vol. 70, No. 9.

Bonsu, N. O. \& Lutta, J. G. M. 2016. 'CEO Cash Compensation and Firm Performance: An Empirical Study From Emerging Markets'. Business and Economic Research. Vol. 6, No.2.

Carpenter, M. A. \& Sanders, Wm. G. 2002. 'Top Management Team Compensation: The Missing Link between CEO Pay and Firm Performance?'. Strategic Management Journal. Vol. 23, No. 4.

Cao, Jerry, X., Lemmon, M., Tian, G. \& Pan, X. 2009. 'Political Promotion, CEO Compensation, and Their Effect on Firm Performance'. Research Collection Lee Kong Chian School of Business. Demirer, I. \& Yuan, J. 2013. 'Executive Compensation Structure and Firm Performance in U.S. Restaurant Industry: An Agency Theory’. Journal of Foodservice Business Research. Vol. 16, hh. 421-438.

Deysel \& Kruger. 2015. 'The Relationship Between South African CEO Compensation and Company Performance In The Banking Industry'. Southern African Business Review. Vol. 19, No. 1.

Fitria, R., Idris, A. \& Kusuma, A.R. 2014. 'Pengaruh Remunerasi, Motivasi dan Kepuasan Kerja Terhadap Kinerja Pegawai di Kantor Pengadilan Tinggi Agama Samarinda'. eJournal Administrative Reform. Vol. 2, No. 3, hh. 1691-1704.

Ghosh, A. 2006. 'Determination of Executive Compensation in an Emerging Economy: Evidence in India'. Emerging Markets Finance and Trade. Vol. 42, No. 3. 
Hariandja, M. T. E. 2002. Manajemen Sumber Daya Manusia. Jakarta: PT Gramedia Widiasarana Indonesia.

Heskett, J. L., Jones, T. O., Loveman, G W., Sasser, W. E. \& Schlesinger, L. A. 1994. 'Putting the Service-Profit Chain to Work'. Harvard Business Review.

Hukum Online. 2007. UUPT 2007 Pertegas Tanggung Jawab Direksi dan Komisaris. Diakses pada 12 April 2018. http://www.hukumonline.com/berita/baca/hol17807/uupt-2007-pertegastanggung-jawab-direksi-dan-komisaris.

Huse, M. 2007. Boards, Governance, and Value Creation. Cambridge University Press.

Hutapea, P. \& Thoha, N. 2008. Kompetensi Plus: Teori, Desain, Kasus dan Penerapan untuk HR serta Organisasi yang Dinamis. Jakarta: PT Gramedia Pustaka Utama.

Idris, A. 2016. Pengantar Ekonomi Sumber Daya Manusia Edisi 1. Yogyakarta: Deepublish.

Iskan, D. 2013. Kerja Bahagia Pensiun Sejahtera: Berdasarkan Pengalaman Nyata. Jakarta: PT Elex Media Komputindo.

Ismail, S.B., Yabai, N. V. \& Hahn, L. J. 2014. 'Relationship Between CEO Pay and Firm Performance: Evidences From Malaysia Listed Firms'. Journal of Economics and Finance. Vol. 3.

Jensen, M.C. \& Meckling, W.H. 1976. 'Theory of The Firm: Managerial Behavior, Agency Costs, and Ownership Structure'. Journal of Financial Economics. Vol. 3.

KBBI Daring. 2016. Arti Kompensasi. Diakses pada 18 Februari 2018. https ://kbbi.kemdikbud.go.id/entri/kompensasi.

Khaparde, R. \& Chincolkar, S. 2013. 'Is There Any Relationship Between Salary and Staff Welfare Expenses and The Performance of The Company?'. International Journal Management Research and Business Strategy. Vol. 2, No. 4.

Kostyuk, A., Stiglbauer, M. \& Govorun, D. 2016. The Theory and Practice of Directors' Remuneration: New Challenges and Opportunities. United Kingdom: Emerald Group Publishing Limited. 
Krauter, E. 2013. 'Executive Remuneration and Financial Performance: a Study of Brazilian Companies'. Journal of Education and Research in Accounting. Vol. 7, No. 3, hh. 249-262.

Kutum, I. 2015. 'Is There A Relation Between CEO Remuneration and Banks' Size and Performance?'. International Journal of Accounting and Financial Reporting. Vol. 5, No. 1.

Muller, V. O. 2014. Do corporate board compensation characteristics influence the financial performance of listed companies?. Procedia: Social and Behavioural Sciences.

Naciri, A. 2010. Internal and External Aspects of Corporate Governance. New York: Routledge.

Ogbeide, S. \& Akanji, B. 2016. 'Executive Remuneration and the Financial Performance of Quoted Firms: The Nigerian Experience'. Management and Economic Review. Vol. 1, No. 2.

Otoritas Jasa Keuangan Republik Indonesia (8 Desember 2014). 2014. POJK Nomor 33/POJK.04/2014 Tentang Direksi dan Dewan Komisaris Emiten atau Perusahaan Publik. https ://www.ojk.go.id/id/regulasi/Pages/POJK-tentang-Direksi-dan-Dewan--KomisarisEmiten-atau-Perusahaan-Publik.aspx.

Oxford Dictionaries. 2018. Reward Definition. Diakses pada 7 Mei 2018. https ://en.oxforddictionaries.com/definition/reward.

Pearce, J.A. \& Robinson R.B. 2007. Manajemen Strategis: Formulasi, Implementasi dan Pengendalian. Ed. 10, Buku 1. Jakarta: Penerbit Salemba Empat.

Prasetyantoko, A. 2013. Corporate Governance: Pendekatan Institusional. Jakarta: PT Gramedia Pustaka Utama.

Prasidhanto, W., 2012. 'Pedoman Penetapan Remunerasi Eksekutif BUMN: Masihkah Relevan?'. Jurnal Riset \& Informasi: Membangun Kebijakan Berbasis Analisa, Keasdepan Riset \& Info Kementrian BUMN. Ed 4. Hh. 26-36.

Smirnova, A. S. \& Zavertiaeva, M. A. 2017. 'Which came first, CEO Compensation or Firm Performance? The Causality Dilemma in European Companies'. Research in International Business and Finance. Vol. 42, hh. 658-673.

Smith, A. 1776. An Inquiry Into The Nature And Causes of The Wealth of Nations. Metalibri. 


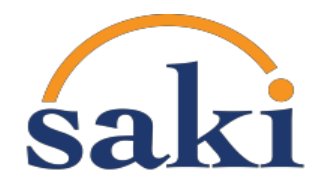

Solomon, J. 2004. Corporate Governance and Accountability. England: John Wiley and Sons, Ltd.

Spremann, K., Ballwieser \& Bamberg, G. 1987. Agency Theory, Information, and Incentives. $1^{\text {st }}$ Ed.

Standar Akuntasi Keuangan, Dewan. 2010. PSAK 24 (revisi 2010) Pernyataan Standar Akuntansi Keuangan: Imbalan Kerja. Jakarta: Ikatan Akuntan Indones ia.

Subekti, I. \& Sumargo, D.W. 2015. 'Family Management, Executive Compensation, and Financial Performance of Indonesian Listed Companies'. Procedia: Social and Behavioural Sciences. Hh. $578-584$.

Suyanto, M. 2007. Strategic Management Global Most Admired Companies: Perusahaan yang Paling Dikagumi Dunia. Yogyakarta: Andi Offset. 